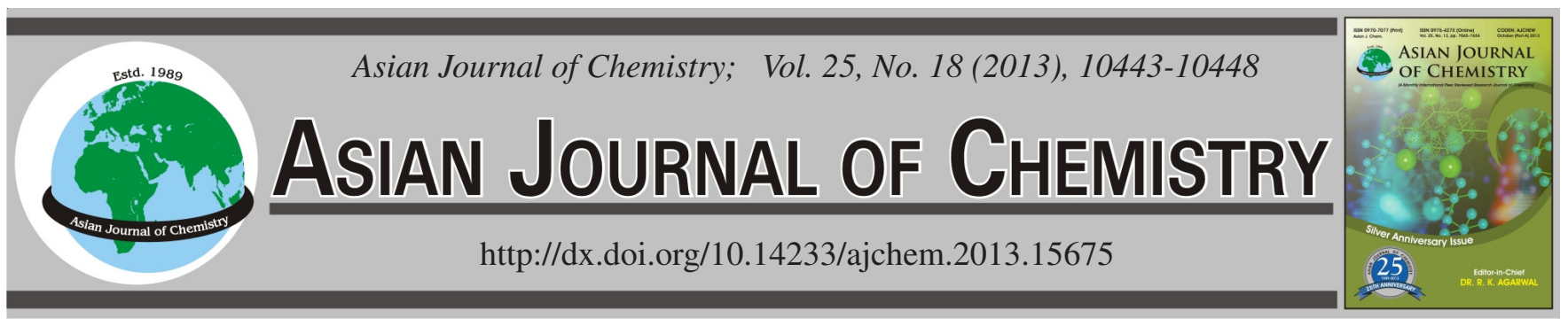

\title{
Adsorption of Nitenpyram and $p$-Cresol from Water in Binary Components System with Modified Resin with Tannic Acid
}

\author{
Xiuhong Wu, Xuehua Zhang, Hongmei Zhang and Zhenghao Fei ${ }^{*}$
}

Jiangsu Provincial Key Laboratory of Coastal Wetland Bioresources and Environmental Protection, College of Chemistry and Chemical Engineering, Yancheng Teachers University, Yancheng 224051, P.R. China

*Corresponding author: Fax: +86 515 88233882; Tel: +86 13805106765; E-mail: feizhenghao@163.com; sunnywuxh@163.com

(Received: 23 April 2013;

Accepted: 20 November 2013)

AJC-14423

\begin{abstract}
The adsorption behaviour of nitenpryram and $p$-cresol in water onto the resin modified with tannic acid based was investigated by static adsorption experiments at different temperature $(288,303,318 \mathrm{~K})$ in single component and binary components system. The adsorption capacities and adsorption selectivity for nitenpryram and $p$-cresol in water were tested. The results show that the adsorption is fitted better by Freundlich model than Langmuir model. The adsorption of nitenpryram on the resin modified with tannic acid was an endothermic process by the positive adsorption enthalpy and an exothermic process of $p$-cresol with the negative adsorption enthalpy. The resin had better absorbability for nitenpryram than for $p$-cresol and the adsorption selectivity of nitenpryram was larger than one. Gibbs free energy, enthalpy change and entropy change had changed in binary components system, to demonstrate the existence of the cooperative effect. A high removal rate of 48.55-94.26\% was obtained for nitenpryram and 28.93-71.71\% for $p$-cresol in single component system, which was lower in binary components system. But in binary components system of the same initial concentration of nitenpryram and $p$-cresol, when the equilibrium concentration was higher, the cooperative adsorption existed, which may be due to the hydrogen bonding or weak acidbase interaction between nitenpryram and $p$-cresol. The competitive adsorption existed, because the adsorption of nitenpryram onto the resin had just smaller change in the presence of $p$-cresol, but the adsorption of $p$-cresol was weakened in the presence of nitenpryram.
\end{abstract}

Key Words: Adsorption resin, Nitenpyram, $p$-Cresol, Binary components system, Cooperative adsorption.

\section{INTRODUCTION}

Pesticides are widely used to control the plant pests ${ }^{1}$. Nitenpryram (Fig. 1) is a new nicotine insecticide with high and fast effectiveness, destroys insects widely, has a persistent efficiency period for 50 days and better solubility under room temperature ${ }^{2}$. There is a serious need for the high-tech about the economic, efficient, feasible wastewater treatment, to protect the environment. Resin adsorption is widely used in wastewater treatment ${ }^{3}$, which makes resin adsorption technology has irreplaceable characteristics because of the designability and selectivity of resin's chemical or physical structures on practical application ${ }^{4,5}$. It offers most effective technology in the field of removal of organic substance. Compared with the single component adsorption, the adsorption rule is complicated and few papers were reported in binary component system in aqueous solution ${ }^{6-11}$. The paper focuses on the adsorption of nitenpryram in aqueous solution on the resin modified with tannic acid ${ }^{12}$ and the adsorption behaviour of bicomponent pollutants coexisting in water, modified adsorption resin as adsorbent, nitenpryram (Fig. 1) and p-cresol as adsorbates through static adsorption. A thermodynamical study is also made.<smiles>CCC(Cc1ccc(Cl)nc1)/C(=C/[N+](=O)[O-])NC</smiles>

Fig. 1. Structure of nitenpryram

\section{EXPERIMENTAL}

Methanol is of G.R. grade. Both $p$-cresol and nitenpyram are of A.R. grade and the resin of is modified with tannic acid based on NDA $150^{12}$.

Static adsorption experiment: A bottle point isotherm procedure was used to conduct all the equilibrium studies in single component system. $0.1 \mathrm{~g}$ of the resin was directly weighed accurately. The adsorbents were contacted, in $250 \mathrm{~mL}$ stoppered conical flasks, with $100 \mathrm{~mL}$ of $p$-cresol or nitenpyram solution of certain concentration $\left(\mathrm{C}_{0}, \mathrm{mg} / \mathrm{L}\right)$ ranging from 100 to $500 \mathrm{mg} / \mathrm{L}$. The flasks were completely sealed and then placed in an incubator shaker at different temperatures (288, 303, $318 \mathrm{~K}$ ) until equilibrium was achieved. 
Experiments of binary solute isotherms were performed according to the above procedure. The main differences were that the initial concentrations of nitenpyram and $p$-cresol were equal to each other in the range of 50-250 mg/L. Other binary solute isotherms were also performed following the above procedure. The main differences were that the initial concentrations of nitenpyram were constant at $300 \mathrm{mg} / \mathrm{L}$ and those of $p$-cresol were in the range of $100-500 \mathrm{mg} / \mathrm{L}$. Conversely, the initial concentrations of $p$-cresol were constant at 300 $\mathrm{mg} / \mathrm{L}$.

\section{RESULTS AND DISCUSSION}

\section{Static adsorption in single component system}

Static adsorption of nitenpryram and $p$-cresol in single component system: Equilibrium adsorption isotherms of the single solute of nitenpyram and $p$-cresol onto the resin are presented in Fig. 2. The isotherm corresponding to higher temperature lies above, which shows the endothermic process, with higher adsorption amounts at lower temperature for nitenpyram, but for $p$-cresol it is the exothermic process.
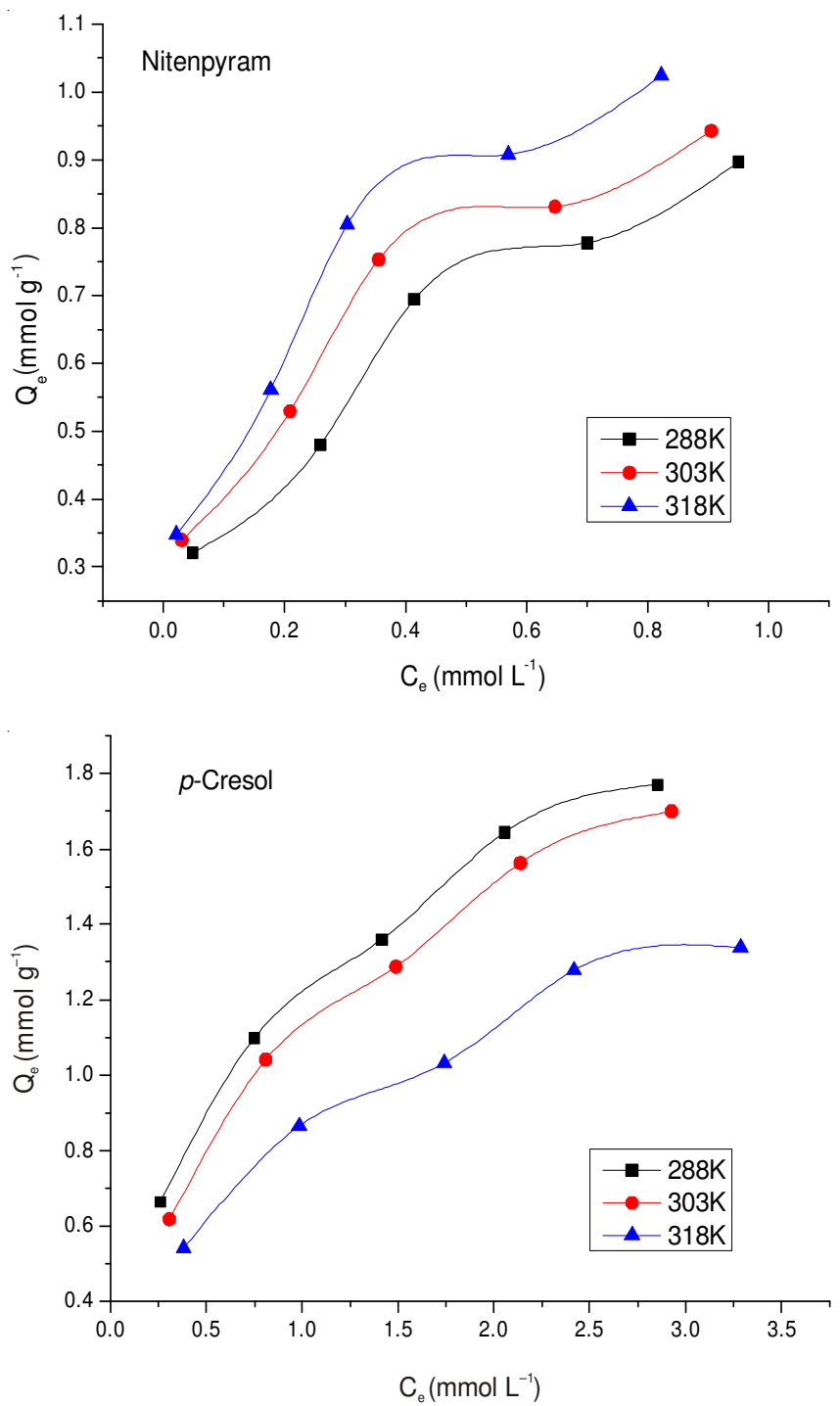

Fig. 2. Equilibrium adsorption isotherms of nitenpyram and $p$-cresol in single component system on the resin at $288-318 \mathrm{~K}$
A high removal rate of 48.55-94.26\% was obtained for nitenpryram studied, as shown in Fig. 3, which may be attributed to the relatively stronger interaction between the acid groups on the adsorbent and the basic groups of the solute at the adsorption process. But with the increasing adsorption capacities there are some shields for the limited amount of adsorption sites or basic functional groups for the higher removal rate on the lower concentration and the higher temperature. But removal efficiency (28.93-71.71\%) was obtained for $p$-cresol studied from Fig. 3, which results from initial higher concentration.
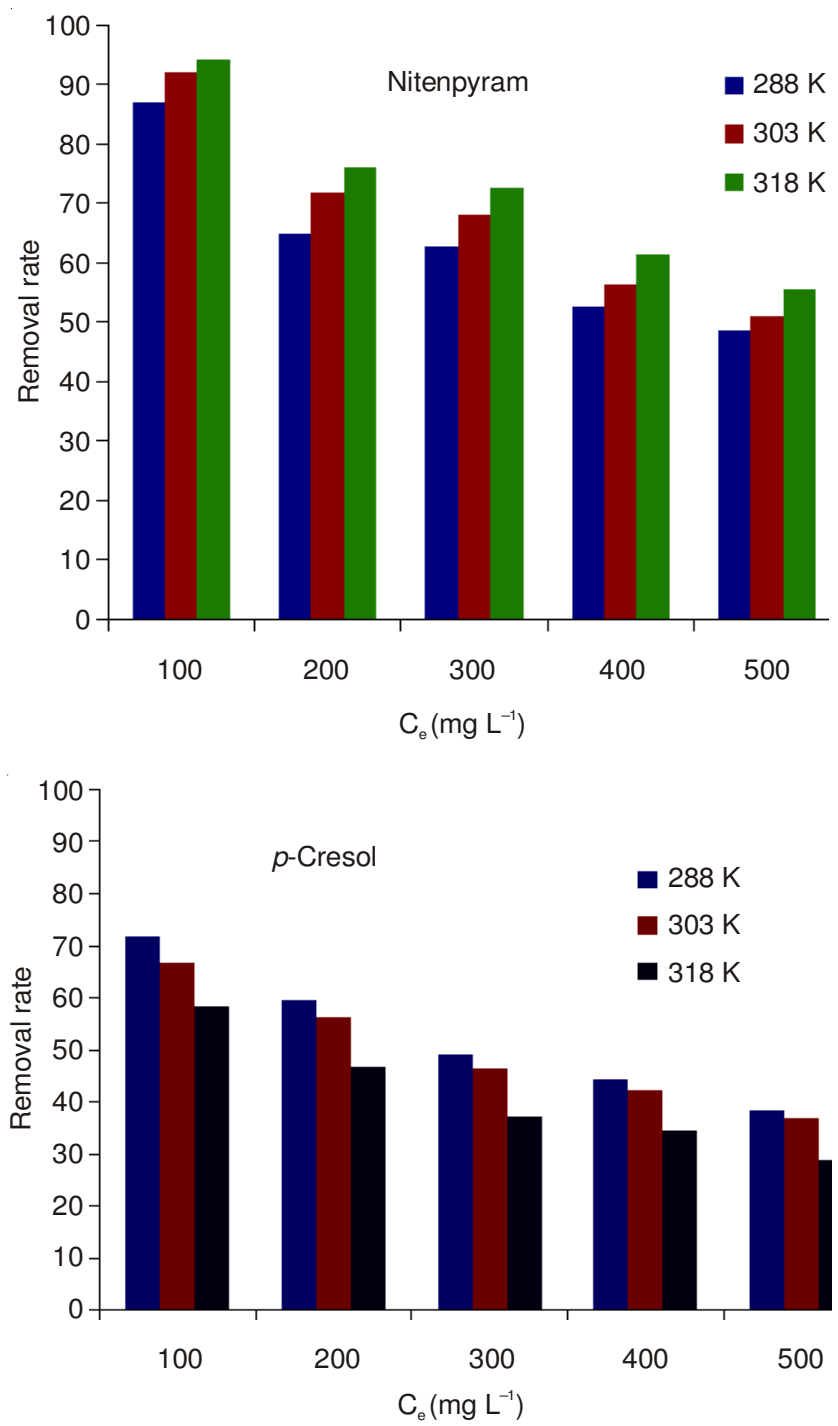

Fig. 3. Removal rate of nitenpyram or $p$-cresol at different temperatures and initial solute concentrations in single component system

Many theories, used to model the adsorption process with varying degrees of success, have been proposed to explain the adsorption phenomenon and to describe the adsorption isotherm relationships. Among them the Langmuir and Freundlich models have been widely used and their linear forms are given below respectively ${ }^{13}$.

Langmuir model: $\mathrm{C}_{\mathrm{e}} / \mathrm{Q}_{\mathrm{e}}=\mathrm{C}_{\mathrm{e}} / \mathrm{M}+1 /\left(\mathrm{MK}_{\mathrm{L}}\right)$

Freundlich model: $\log \mathrm{Q}_{\mathrm{e}}=\log \mathrm{K}_{\mathrm{f}}+1 / \mathrm{n} \log \mathrm{C}_{\mathrm{e}}$

where $\mathrm{M}, \mathrm{K}_{\mathrm{L}}, \mathrm{K}_{\mathrm{f}}$ and $n$ are characteristic constants. The Langmuir constant $\mathrm{M}(\mathrm{mmol} / \mathrm{g})$ is the maximum amount per 
weight of adsorbent to form a complete monolayer on the surface bound and $\mathrm{K}_{\mathrm{L}}(\mathrm{L} / \mathrm{g})$ is a constant related to the affinity of the binding sites. The Freundlich coefficient $\mathrm{K}_{\mathrm{f}}(\mathrm{L} / \mathrm{mmol})$ is an index of the sorption capacity of the resins and the Freundlich exponent ' $n$ ' (dimensionless) denotes the heterogeneity of the surface and the intensity of adsorption.

By a non-linear least square routine, the regression equations corresponding to the above isotherms can be obtained and their constants along with the correlation coefficients $r$ are summarized in Table-1. The results clearly show that the adsorption data for the studied adsorption systems of nitenpyram fits better to the Freundlich model and to $p$-cresol, both.

As seen from the values of $M$ and $K_{L}$ in Table-1, the capacity of nitenpyram increases with increasing initial lead concentration, temperature for the interaction between basic groups of nitenpyram and acid groups on the resin modified with tannic acid, maybe share electrons. Conversely, the capacity of $p$-cresol decreases with the increasing temperature, indicating the predominant phenomena of "sorbent-motivated" effects caused mainly by the electrostatic interaction and ion change which are exothermic interactions. And the constant ' $n$ ' is always more than 1 in our study range, indicating a favourable type adsorption.

Thermodynamics: Thermodynamic parameters such as Gibbs free energy $(\Delta \mathrm{G})$, enthalpy change $(\Delta \mathrm{H})$ and entropy change $(\Delta \mathrm{S})$ for the adsorption of nitenpryram and $p$-cresol onto the resin are given in Table- 2 .

$\Delta \mathrm{G}$ is calculated according to eqn. 3 the data onto the resin better fitted to the Freundlich model ${ }^{16}$. Thus, the calculation of $\Delta \mathrm{G}$ in binary components system is the same as in single component system.

$$
\Delta \mathrm{G}=-n \mathrm{RT}
$$

where $n$ is the Freundlich model characteristic constant, $\mathrm{R}$ is the gas constant $(\mathrm{kJ} / \mathrm{mol} \mathrm{K})$ and $\mathrm{T}$ is the absolute temperature $(\mathrm{K})$.

The following Gibbs-Helmholtz equation can be obtained to describe the relation between $\Delta \mathrm{G}$ and the other two thermodynamic parameters.

$$
\Delta \mathrm{G}=\Delta \mathrm{H}-\mathrm{T} \Delta \mathrm{S}
$$

Then, $\Delta H$ can be calculated respectively from the van't Hoff equation.

$$
\ln \left(\mathrm{Q}_{\mathrm{e}} / \mathrm{C}_{\mathrm{e}}\right)=-\Delta \mathrm{H} / \mathrm{RT}+\ln \mathrm{K}_{0}
$$

The estimated enthalpy of adsorption of nitenpryram is positive, indicating the adsorption process is an endothermic one. The enthalpy of $p$-cresol is negative, an exothermic process. Both are low and in the range of $10-40 \mathrm{~kJ} / \mathrm{mol}$ where physical adsorption is expected to be the dominant mechanism.

It is well known that the free energy change value for a physical sorption, which is in the range of -20 to $0 \mathrm{~kJ} / \mathrm{mol}$. A chemical sorption process is in the range of -400 to $-50 \mathrm{~kJ} /$ mol. The free energy changes are small (Table-2), further confirming the physical character of the adsorption. As expected they are negative in all cases because the solute is more concentrated on the surface of the adsorbents than in the bulk solutions. The magnitude of the free energy changes indicates the stronger adsorption force between the resin and nitenpryram for the partially polar groups in its net work, with the results of equilibrium static adsorption.

The negative values of the adsorption entropy are consistent with the restricted mobility of the adsorbed $p$-cresol molecules compared with those in solution. Thus a more ordered arrangement of solute molecules for $p$-cresol is formed on the surface of the resin modified with tannic acid. But for nitenpryram the values of the adsorption entropy is positive, so the adsorption is driven by enthalpy and an irreversible process.

\section{Static adsorption in binary components system}

Same initial concentration of nitenpyram and $p$-cresol in binary components system: Equilibrium adsorption isotherms of nitenpyram and $p$-cresol onto the resin in binary components system are presented in Fig. 4. For nitenpryram, temperature has little effect on the attachment. It shows good treatment efficiency in Fig. 5.

\begin{tabular}{|c|c|c|c|c|c|c|c|}
\hline \multicolumn{8}{|c|}{$\begin{array}{c}\text { TABLE-1 } \\
\text { FITTED RESULTS FOR LANGMUIR AND FREUNDLICH MODELS IN SINGLE COMPONENT SYSTEM }\end{array}$} \\
\hline \multirow{2}{*}{ Regression Requations } & \multirow{2}{*}{ Parameters } & \multicolumn{3}{|c|}{ Nitenpyram } & \multicolumn{3}{|c|}{$p$-Cresol } \\
\hline & & $288 \mathrm{~K}$ & $303 \mathrm{~K}$ & $318 \mathrm{~K}$ & $288 \mathrm{~K}$ & $303 \mathrm{~K}$ & $318 \mathrm{~K}$ \\
\hline \multirow{3}{*}{ Langmuir } & $\mathrm{M}$ & 10.787 & 19.157 & 26.882 & 3.769 & 2.857 & 2.119 \\
\hline & $\mathrm{K}_{\mathrm{L}}$ & 0.073 & 0.043 & 0.032 & 0.520 & 0.699 & 0.740 \\
\hline & $\mathrm{r}$ & 0.944 & 0.949 & 0.949 & 0.995 & 0.998 & 0.994 \\
\hline \multirow{3}{*}{ Freundlich } & $\mathrm{K}_{\mathrm{f}}$ & 0.883 & 0.954 & 1.069 & 1.187 & 1.084 & 0.834 \\
\hline & $\mathrm{n}$ & 2.869 & 3.311 & 3.340 & 2.406 & 2.206 & 2.325 \\
\hline & $\mathrm{r}$ & 0.980 & 0.985 & 0.985 & 0.996 & 0.998 & 0.994 \\
\hline
\end{tabular}

Higher removal efficiency rate was obtained for nitenpryram (Fig. 5), in the range of 55.16-98.47\%, but for $p$-cresol just in

TABLE-2

\begin{tabular}{|c|c|c|c|c|c|}
\hline Adsorbate & $\mathrm{q}_{\mathrm{e}}(\mathrm{mmol} / \mathrm{g})$ & Temperature (K) & $\Delta \mathrm{H}(\mathrm{kJ} / \mathrm{mol})$ & $\Delta \mathrm{S}(\mathrm{J} / \mathrm{mol} \mathrm{K})$ & $\Delta \mathrm{G}(\mathrm{kJ} / \mathrm{mol})$ \\
\hline \multirow{3}{*}{ Nitenpyram } & 1.0 & 288 & 14.616 & 74.604 & -6.870 \\
\hline & 1.0 & 303 & 14.616 & 75.766 & -8.341 \\
\hline & 1.0 & 318 & 14.616 & 73.729 & -8.830 \\
\hline \multirow{3}{*}{$p$-Cresol } & 1.0 & 288 & -20.974 & -52.823 & -5.761 \\
\hline & 1.0 & 303 & -20.974 & -50.881 & -5.557 \\
\hline & 1.0 & 318 & -20.974 & -46.616 & -6.150 \\
\hline
\end{tabular}

THERMODYNAMIC PARAMETERS FOR ADSORPTION OF NITENPRYRAM OR $p$-Cresol ONTO THE RESIN IN SINGLE COMPONENT SYSTEM 

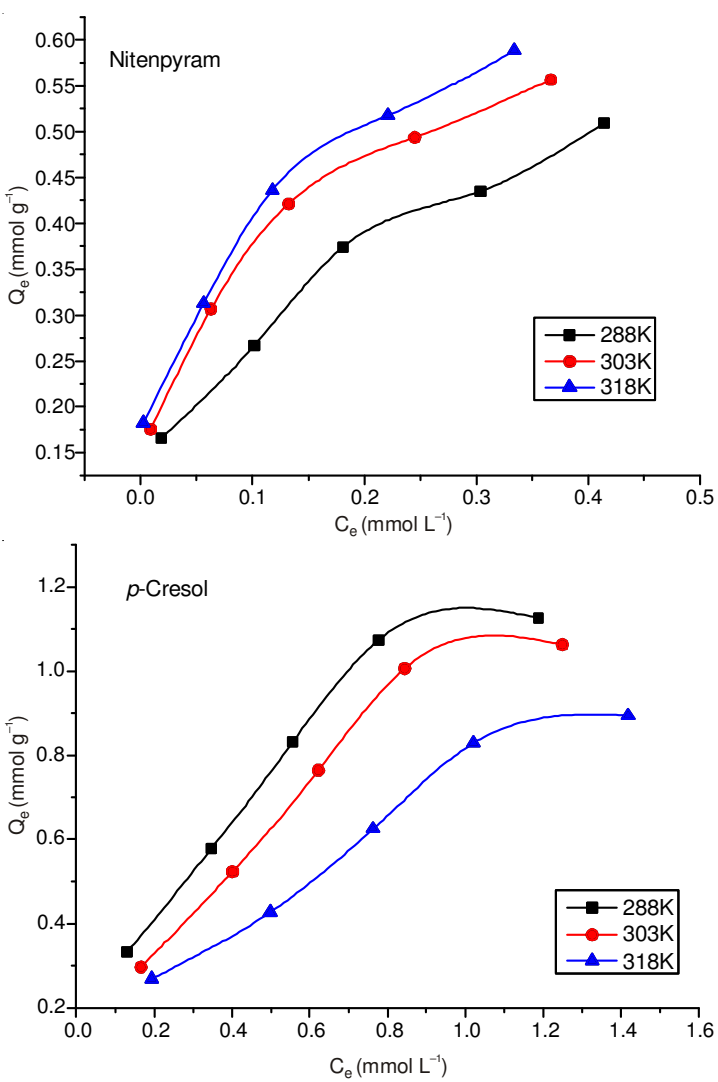

Fig. 4. Equilibrium adsorption isotherms of nitenpryram or $p$-cresol in binary components system
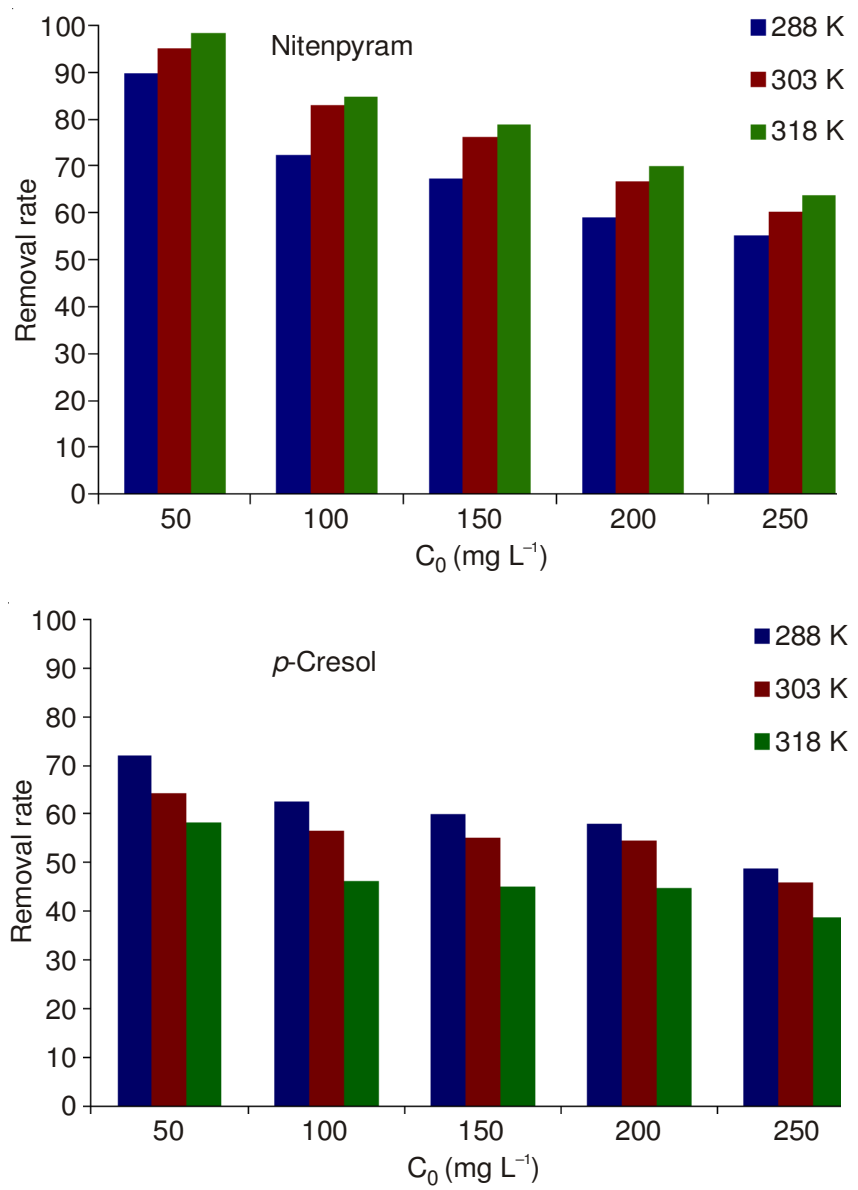

Fig. 5. Removal rate of nitenpryram or $p$-cresol at different initial solute concentrations in binary components system the range of $38.68-72 \%$. Compared with the results of the single component system, the capacity of the resin has been improved better in binary components system.

Contrasting Fig. 6 of the binary components system with Fig. 2, the adsorption capacity of $p$-cresol and nitenpryram in binary components system were more than the adsorption capacity in single component system (nitenpryram or $p$-cresol) on the resin at the same higher equilibrium concentration, which would be due to the cooperative effect primarily arisen from the acid-base interaction between nitenpryram and $p$-cresol; when the equilibrium concentration (e.g., $0.4 \mathrm{mmol}$ $\mathrm{L}^{-1}$ ) was lower in Fig. 6, the capacity was less than it in Fig. 2, because of the competition on the adsorption locus, these molecules were organized in the arrangement out of disorder. From Fig. 4 and Table-3, in binary components system the equilibrium adsorption isotherms could also be fitted by Freundlich model better than Langmuir model, the values of $n$ and $\mathrm{K}_{\mathrm{f}}$ was lower than them in Table-1, $r$ was greater than 0.988 and Fig. 5 also provided data supporting for the cooperative effect, with higher removal rate.

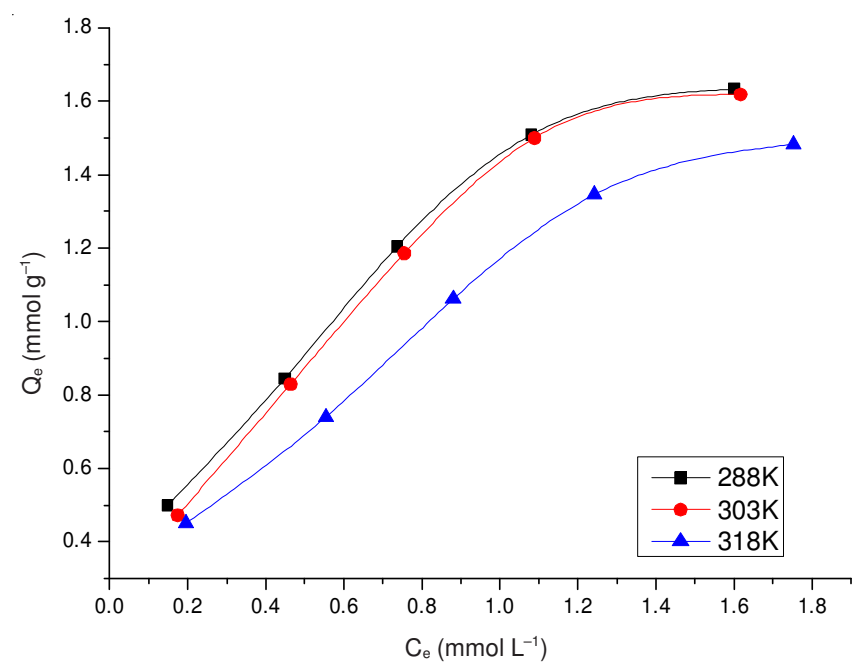

Fig. 6. Equilibrium adsorption isotherms of both nitenpryram and $p$-cresol on ZHP02 in binary components system

Thermodynamic parameters such as Gibbs free energy $(\Delta \mathrm{G})$, enthalpy change $(\Delta \mathrm{H})$ and entropy change $(\Delta \mathrm{S})$ for the adsorption of nitenpryram and $p$-cresol onto the resin with the same initial concentration of nitenpryram and $p$-cresol in binary components system are given in Table-4.

Comparing with the single component system (Table-2), in Table-4 there was variability in the thermodynamic parameters. The enthalpy change and Gibbs free energy of $p$-cresol decreased, but the enthalpy change of nitenpryram increased sharply. The entropy change of nitenpryram was more positive than it in Table-2, that randomness went up in the system, which could favour the adsorption process, further to demonstrate the existence of the cooperative effect.

Simultaneous adsorption in binary components system: For further testifying the above predominant mechanism, the influence of initial concentration on the adsorption capacity was demonstrated in Fig. 7. In general, there was some drop in the adsorption amount of nitenpryram with the increasing initial concentration of $p$-cresol, but larger distinction for 


\begin{tabular}{|c|c|c|c|c|c|c|c|}
\hline \multicolumn{8}{|c|}{$\begin{array}{c}\text { TABLE-3 } \\
\text { FITTED RESULTS FOR LANGMUIR AND FREUNDLICH M }\end{array}$} \\
\hline \multirow{2}{*}{ Adsorbate } & \multirow{2}{*}{$\begin{array}{l}\text { Tempreature } \\
\text { (K) }\end{array}$} & \multicolumn{3}{|c|}{ Langmuir } & \multicolumn{3}{|c|}{ Freundlich } \\
\hline & & $\mathrm{M}$ & $\mathrm{K}_{\mathrm{L}}$ & $\mathrm{r}$ & $\mathrm{K}_{\mathrm{f}}$ & $\mathrm{n}$ & $\mathrm{r}$ \\
\hline \multirow{3}{*}{ Nitenpryram } & 288 & 13.532 & 0.033 & 0.960 & 0.676 & 2.746 & 0.992 \\
\hline & 303 & 28.985 & 0.016 & 0.971 & 0.773 & 3.134 & 0.998 \\
\hline & 318 & 86.207 & 0.011 & 0.985 & 1.899 & 2.525 & 0.993 \\
\hline \multirow{3}{*}{$p$-Cresol } & 288 & 3.211 & 0.482 & 0.992 & 1.121 & 1.702 & 0.988 \\
\hline & 303 & 2.120 & 0.843 & 0.994 & 1.009 & 1.487 & 0.988 \\
\hline & 318 & 1.726 & 0.709 & 0.980 & 0.741 & 1.564 & 0.988 \\
\hline \multirow{3}{*}{ Nitenpryram $+p$-Cresol } & 288 & 4.427 & 0.432 & 0.987 & 1.356 & 1.902 & 0.993 \\
\hline & 303 & 3.384 & 0.649 & 0.994 & 1.329 & 1.716 & 0.992 \\
\hline & 318 & 2.973 & 0.609 & 0.984 & 1.115 & 1.756 & 0.994 \\
\hline
\end{tabular}

\begin{tabular}{|c|c|c|c|c|c|}
\hline \multicolumn{6}{|c|}{$\begin{array}{l}\text { TABLE- } 4 \\
\text { THERMODYNAMIC PARAMETERS FOR THE ADSORPTION OF NITENPRYRAM AND } p \text {-CRESOL ONTO } \\
\text { THE RESIN ZHP02 WITH THE SAME INITIAL CONCENTRATION IN BINARY COMPONENTS SYSTEM }\end{array}$} \\
\hline Adsorbate & $\mathrm{Q}_{\mathrm{e}}(\mathrm{mmol} / \mathrm{g})$ & Temperature $(\mathrm{K})$ & $\Delta \mathrm{H}(\mathrm{kJ} / \mathrm{mol})$ & $\Delta \mathrm{S}(\mathrm{J} / \mathrm{mol} \mathrm{K})$ & $\Delta \mathrm{G}(\mathrm{kJ} / \mathrm{mol})$ \\
\hline \multirow{3}{*}{ Nitenpryram } & 1.0 & 288 & 65.523 & 250.3 & -6.575 \\
\hline & 1.0 & 303 & 65.523 & 242.3 & -7.895 \\
\hline & 1.0 & 318 & 65.523 & 227.0 & -6.676 \\
\hline \multirow{3}{*}{$p$-Cresol } & 1.0 & 288 & -16.705 & -43.85 & -4.075 \\
\hline & 1.0 & 303 & -16.705 & -42.77 & -3.746 \\
\hline & 1.0 & 318 & -16.705 & -39.53 & -4.135 \\
\hline \multirow{3}{*}{ Nitenpryram $+p$-Cresol } & 1.0 & 288 & -9.725 & -17.95 & -4.554 \\
\hline & 1.0 & 303 & -9.725 & -17.83 & -4.323 \\
\hline & 1.0 & 318 & -9.725 & -15.98 & -4.643 \\
\hline
\end{tabular}

$p$-cresol with the increasing initial concentration of nitenpryram, competitive adsorption phenomenon existed. The change of nitenpryram' concentration had greater effect on the adsorption of $p$-cresol onto the resin modified with tannic acid, because of the stronger interaction between nitenpryram and the resin. Contrasting Fig. 8 with Fig. 2, the results were consistent with the data that the adsorption effect was related to temperature. The capacity of nitenpryram and $p$-cresol on the resin was in decreasing order, demonstrated the competition in the adsorption locus once again.

Selectivity index: Selectivity index often used to evaluate an adsorbent or an adsorptive process. If we define the distribution coefficient (solid-to-liquid) as:

$$
\mathrm{D}=\mathrm{Q}_{\mathrm{e}} / \mathrm{C}_{\mathrm{e}}
$$

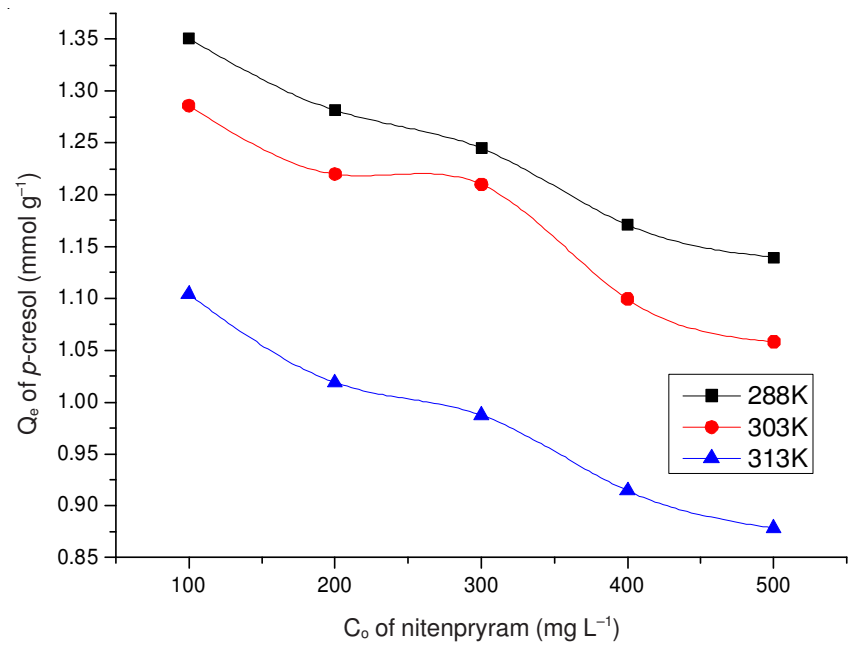

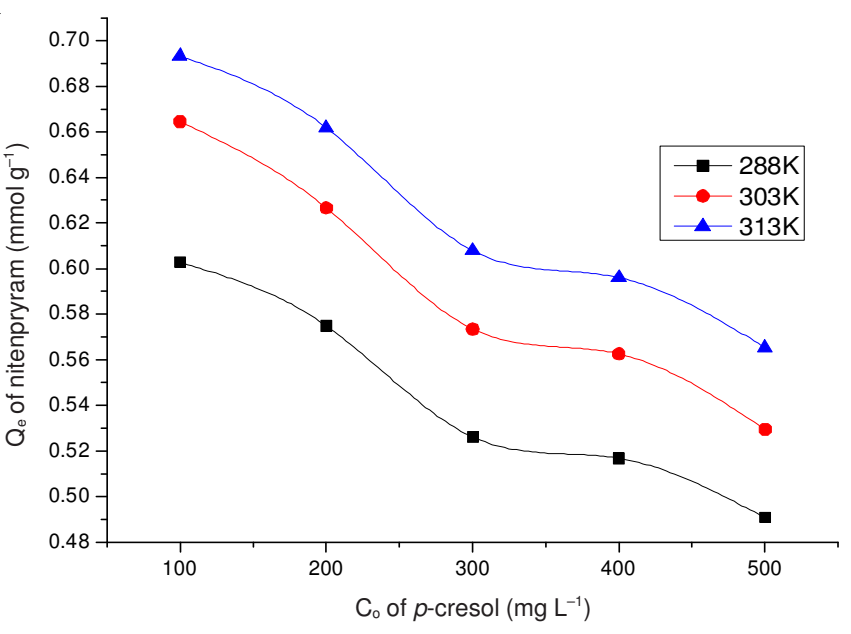

Fig. 7. Influence of initial concentration on the adsorption amount onto the resin from the binary components adsorptive environment

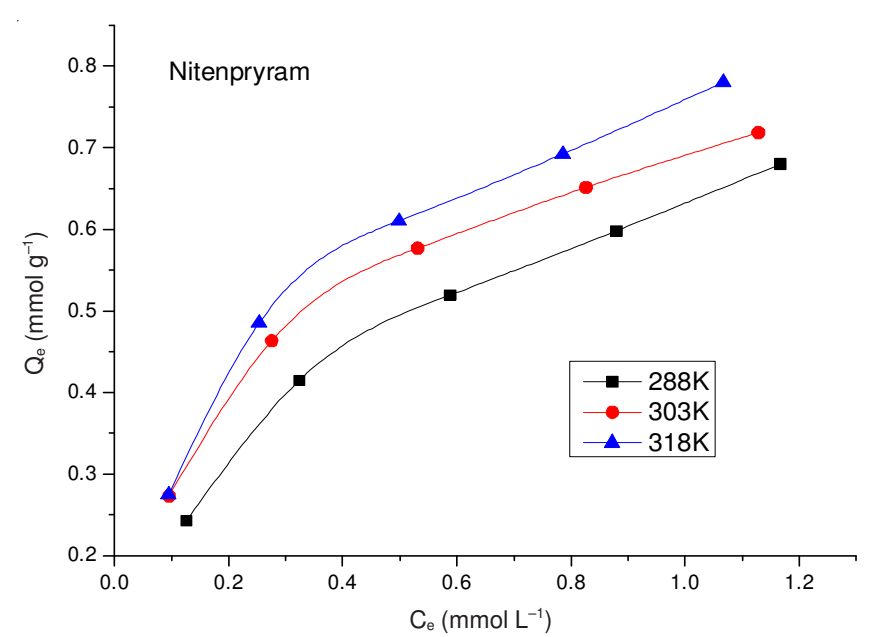




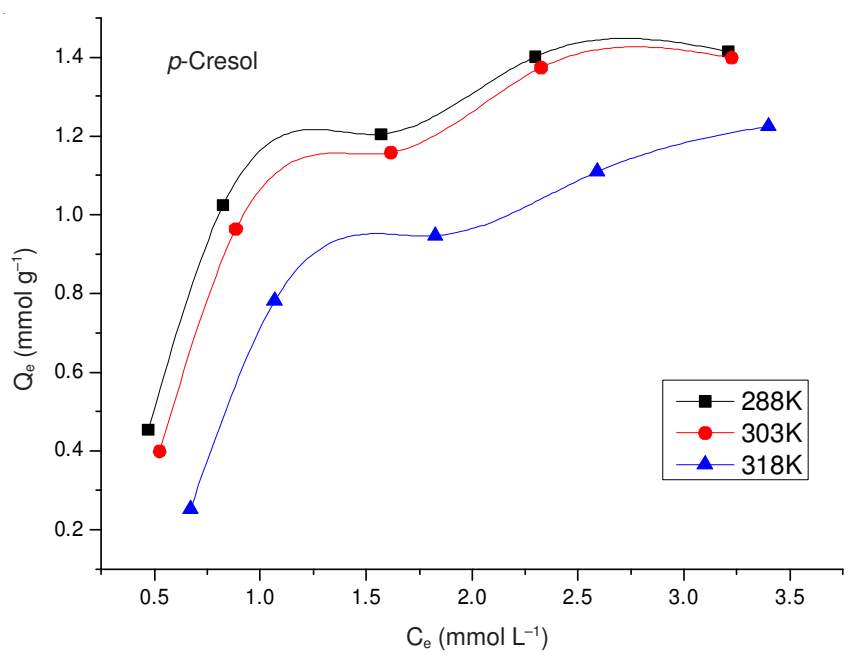

Fig. 8. Equilibrium adsorption isotherms of nitenpryram or $p$-cresol in binary components system with the constant initial concentration of another adsorbate at $300 \mathrm{mg} / \mathrm{L}$

Then the selectivity index of the first component has the following form:

$$
\mathrm{S}_{1 / 2}=\mathrm{D}_{1} / \mathrm{D}_{2}
$$

$\mathrm{D}_{1}$ and $\mathrm{D}_{2}$ represent the distribution coefficient of two solutes respectively ${ }^{12}$.

The selectivity indexes for the adsorption of nitenpryram onto the adsorbent tested are compared in Table-5, with 300 $\mathrm{mg} / \mathrm{L}$ of $p$-cresol as the competitive component. It can be seen that the adsorption selectivity of nitenpryram on the resin is larger than one on higher temperature with lower concentrations, contributed to the larger difference in the adsorbentsolute interaction and solvent-solute interaction. Consequently, it is expected to apply the resin for the successful separation and recovery of nitenpryram from the water containing $p$-cresol. The proposed technique has its practicability.

\begin{tabular}{cccc}
\multicolumn{4}{c}{ TABLE-5 } \\
SELECTIVITY INDEX OF NITENPRYRAM \\
\hline $\mathrm{C}_{0}$ of nitenpryram \\
\cline { 2 - 4 }$(\mathrm{mg} / \mathrm{L})$
\end{tabular}

\section{Conclusion}

The adsorption was fitted by Freundlich model better than Langmuir model, with higher linearity. The adsorption of nitenpryram on the resin modified with tannic acid was an endothermic process by the positive adsorption enthalpy and an exothermic process of $p$-cresol with the negative adsorption enthalpy. The resin had better absorbability for nitenpryram than for $p$-cresol and the adsorption selectivity of nitenpryram was larger than one. Gibbs free energy, enthalpy change and entropy change had changed in binary components system, to demonstrate the existence of the cooperative effect. A high removal rate of 48.55-94.26\% was obtained for nitenpryram and 28.93-71.71\% for $p$-cresol in single component system, which was lower in binary components system. But in binary components system of the same initial concentration of nitenpryram and $p$-cresol, when the equilibrium concentration was higher, the cooperative adsorption existed, which may be due to the hydrogen bonding or weak acid-base interaction between nitenpryram and $p$-cresol. The competitive adsorption existed, because the adsorption of nitenpryram onto the resin had just smaller change in the presence of $p$-cresol, but the adsorption of $p$-cresol was weakened in the presence of nitenpryram.

\section{ACKNOWLEDGEMENTS}

The work was financially supported by the National Natural Science Foundation of China (21201147), sponsored by research fund of Jiangsu Provincial Key Laboratory of Coastal Wetland Bioresources and Environmental Protection (JLCBE12010).

\section{REFERENCES}

1. J.-G. Feng, X.-J. Zhang, C. Yu, W.-T. Chen, M.-L. Cai and X.-M. Wu, J. China Agric. Univ., 02, 220 (2013).

2. M. Li, S.-X. Cheng, H.-P. Li, T. Li, J.-X. Chen and H.-X. Gao, Agrochem. Res. Appl., 02, 1 (2012).

3. D.B. Cheng, X.-L. Yu and X.-M. Yu, J. Wuhan Inst. Technol., 09, 20 (2011).

4. Y. Matsui, D.R.U. Knappe and R. Takagi, Environ. Sci. Technol., 36, 3426 (2002)

5. A.M. Li, Q.X. Zhang, G.C. Zhang, J. Chen, Z. Fei and F. Liu, Chemosphere, 47, 981 (2002).

6. W. Zhang, J. Chen, Q. Zhang and B. Pan, Acta Polym. Sinica, 2, 213 (2006).

7. W.-M. Zhang, J.-L. Chen, Q.-X. Zhang, B.-C. Pan and J.-D. Li, Chinese J. Environ. Sci., 27, 727 (2006).

8. D. Colombié, K. Landfester, E.D. Sudol and M.S. El-Aasser, Langmuir, 16, 7905 (2000).

9. Z.-F. Xie, Y. Chen, Q. Yan, Z.-F. Tong and K.-Q. Yang, Chem. Eng. (China), 39, 44 (2011).

10. F. Liu, M. Xia, X. Cheng, H. Wu, Z. Fei and J. Chen, Environ. Pollut. Control, 08, 570 (2005).

11. F.Q. Liu, Chinese J. Polymer Sci., 04, 373 (2005)

12. Z.-H. Fei, W.-Z. Shi, Z.-X. Li, W.-X. Li, J.-P. Wang, G.-C. Zhang and S.-H. Tang, Polymer Mater. Sci. Eng., 26, 64 (2010).

13. S. Lou, Y. Liu, Q. Bai and D. Di, Progr. Chem., 24, 1427 (2012). 